\title{
Agrowisata Kopi Di Kledung Kabupaten Temanggung Dengan Pendekatan Arsitektur Ekologi
}

\author{
Karlina Hangesti Rahayu, Rachmadi Nugroho, Ana Hardiana \\ Program Studi Arsitektur \\ Fakultas Teknik \\ Universitas Sebelas Maret Surakarta \\ Email : karlinahangestir@gmail.com
}

\begin{abstract}
Temanggung Regency is a regency in Central Java Province. Existing issues in the Temanggung Regency becoming the background of planning and designing Coffee Agrotourism in Kledung Temanggung Regency based on Ecology Architecture, as for instances, the needs of new tourist destinations in the Temanggung Regency, the government's plan to develop new tourist destinations such as agrotourism area, the potential for coffee plants in Kledung, the principle of agrotourism stressed as low negative impact on nature and provides lessons to tourist about the importance of conservation and Kledung region as a region which provides protection underneath and protected areas that need to be preserved geology. The problem of the design is implement the concept of ecology with a focus on energy efficiency, minimazing cut and fill and waste management in the region and building Coffee Agrotourism in an effort to preserve nature. The purpose of this design is to get the design and building of Coffee Agrotourism region as a place of education and recreation on coffee plants by implementing the concept of Ecology Architecture. The method used is is a method of designing architecture based on Ecology Architecture approach. The results obtained Coffee Agrotourism based on Ecology Architecture approach that is applied to energy efficiency, minimazing cut and fill, and waste management.
\end{abstract}

Keywords: Coffee Agrotourism, Ecology Architecture, Energy Efficiency, Cut and fill, Waste Management.

\section{PENDAHULUAN}

Kabupaten Temanggung merupakan kabupaten di Provinsi Jawa Tengah yang memiliki potensi pariwisata. Namun, saat ini posisi Kabupaten Temanggung masih merupakan daerah antar tujuan wisata karena kurangnya pengembangan destinasi wisata baru. Oleh karena itu, pemerintah Kabupaten Temanggung berencana mengubah posisinya menjadi daerah tujuan wisata dengan mengembangkan destinasi wisata baru berupa kawasan agrowisata sesuai dengan potensi yang ada. Rencana pemerintah untuk mengembangkan destinasi wisata baru berupa kawasan agrowisata ini merupakan arah kebijakan umum dan program pembanguan daerah Kabupaten Temanggung Tahun 2013 2018 dalam RPJMD Tahun 2013 - 2018.

Berdasarkan kajian MP3ET 2011 dalam RPJMD Kabupaten Temanggung Tahun 2013 - 2018 sektor perkebunan merupakan salah satu sub sektor agro yang berpotensi dan masih akan berkembang di masa yang akan datang dengan tanaman kopi sebagai salah satu komoditas unggulan. Oleh karena itu, kawasan agrowisata yang direncanakan sebagai destinasi wisata baru Kabupaten Temanggung adalah kawasan Agrowisata Kopi.

$\begin{array}{ccc}\text { Salah satu wilayah Kabupaten } & \text { Kansi } \\ \text { Temanggung } & \text { yang } & \text { memiliki }\end{array}$ perkebunan kopi adalah Kecamatan Kledung. Berdasarkan data UPT Pertanian Kecamatan Kledung dalam Temanggung Dalam Angka 2014 dari 13 desa hanya tiga desa yang tidak memiliki potensi perkebunan kopi. Oleh karena itu, Kecamatan Kledung sesuai sebagai lokasi Agrowisata Kopi. Hal ini juga didukung dengan peruntukkan Kecamatan Kledung sebagai kawasan budidaya peruntukkan pariwisata dalam RTRW Kabupaten Temanggung Tahun $2011-2031$.

Agrowisata merupakan salah satu wisata spesifik yang termasuk dalam ekowisata. Oleh karena itu, Agrowisata berpedoman pada prinsip ekowisata. Menurut Wood, 2002 
(dalam Utama 2014) salah satu prinsip ekowisata adalah menekankan serendahrendahnya dampak negatif terhadap alam dan memberikan pembelajaran kepada wisatawan mengenai pentingnya pelestarian. Menurut Frick (1998:39) arsitektur ekologi tidak menentukan apa yang seharusnya terjadi dalam arsitektur, karena tidak ada sifat khas yang mengikat sebagai standar atau ukuran baku. Namun mencakup keselarasan antara manusia dan alam. Berdasarkan pendoman dan pengertian arsitektur ekologi yang mencakup keselarasan antara manusia dan alam desain Agrowisata Kopi yang direncanakan menerapkan konsep Arsitektur Ekologi. Penerapan Arsitektur Ekologi ini juga didasari atas keberadaan Kledung sebagai kawasan yang memberikan perlindungan di bawahnya dan kawasan lindung geologi yang perlu dijaga kelestariannya.

Agrowisata Kopi yang direncanakan diharapkan dapat menjadi wadah edukasi dan rekreasi mengenai tanaman kopi yang menerapkan konsep Arsitektur Ekologi serta dapat mendukung Kabupaten Temanggung menjadi daerah tujuan wisata.

\section{METODE}

Berdasarkan konsep perencanaan dan perancangan , Agrowisata kopi yang direncanakan menerapkan Arsitektur Ekologi yang fokus pada efisiensi penggunaan energi, meminimalkan cut and fill, dan manajemen limbah. Efisiensi penggunaan energi dalam desain kawasan dan bangunan Agrowisata Kopi diterapkan pada beberapa aspek antara lain aspek pencahayaan dan penghawaan alami, penggunaan solar lamp sebagai pencahayaan buatan dalam kawasan, dan penerapan material lokal. Pencahayaan dan penghawaan alami dimanfaatkan secara maksimal dengan mengondisikan desain bangunan dengan iklim setempat. Mengondisikan desain dengan iklim setempat dilakukan dengan cara menempatkan bukaan berupa jendela pada arah barat dan skylight untuk mengoptimalkan pencahayaan alami serta mendesain massa bangunan yang aerodinamik terhadap pergerakkan angin untuk mengoptimalkan penghawaan alami.

Kondisi tapak yang berkontur membutuhkan adanya cut and fill yang dapat mengakibatkan berubahnya kondisi asli tapak.
Desain struktur panggung dan peletakan massa yang menyesuaikan kontur diterapkan untuk mengurangi cut and fill, sehingga mengurangi perubahan kondisi asli tapak.

Tapak berada di kawasan yang memberikan perlindungan di bawahnya dan kawasan lindung geologi yang perlu dijaga kelestariannya.Oleh karena itu, tapak membutuhkan adanya suatu manajemem limbah yang baik. Manajemen limbah yang baik diterapkan dengan menjamin penyerapan air ke dalam tanah melalui lubang biopori dan ruang terbuka hijau, pengolahan grey water untuk dimanfaatkan kembali sebagai air untuk outdoor hydrant dan flushing toilet, serta pengolahan limbah cair kopi dan ranting kopi untuk dimanfaatkan kembali sebagai biogas dan elemen eksterior.

\section{ANALISIS}

\subsection{Analisis Peruangan}

Kebutuhan ruang yang muncul merupakan pertimbangan dari kegiatan yang dilakukan di dalam agrowisata kopi karena ruang-ruang tersebut nantinya digunakan untuk mewadahi segala kegiatan yang ada di dalam Agrowisata Kopi

Tabel 1.Kebutuhan Ruang Pengelola

\begin{tabular}{|c|c|c|}
\hline PELAKU & KEGIATAN & PERUANGAN \\
\hline \multirow{9}{*}{ Pengelola } & Parkir & Tempat Parkir \\
\hline & $\begin{array}{l}\text { Menyimpan } \\
\text { barang }\end{array}$ & Loker \\
\hline & \multirow{3}{*}{ Bekerja } & R. Direktur \\
\hline & & $\begin{array}{l}\text { R. Manajer dan } \\
\text { Staff }\end{array}$ \\
\hline & & R. MEE \\
\hline & Rapat & R. Rapat \\
\hline & Istirahat & Pantry \\
\hline & Ibadah & Mushola \\
\hline & Metabolisme & Toilet \\
\hline
\end{tabular}

Pada Tabel 1. dapat diketahui ruang-ruang yang dibutuhkan untuk mewadahi kegiatan pengelola dalam Agrowisata Kopi.

Tabel 2.Kebutuhan Ruang Pengunjung

\begin{tabular}{|l|l|l|}
\hline PELAKU & KEGIATAN & PERUANGAN \\
\hline \multirow{3}{*}{$\begin{array}{l}\text { Pengunju } \\
\text { ng }\end{array}$} & Parkir & Tempat Parkir \\
\cline { 2 - 3 } & Masuk & Hall/Lobby \\
\cline { 2 - 3 } & $\begin{array}{l}\text { Mencari } \\
\text { Informasi }\end{array}$ & Front office \\
\hline
\end{tabular}




\begin{tabular}{|l|l|l|}
\hline \multirow{4}{*}{$\begin{array}{l}\text { Membeli } \\
\text { Tiket }\end{array}$} & Loket \\
\cline { 2 - 3 } Coffee Tour & Shelter \\
\cline { 2 - 3 } & Mini Pabrik \\
\cline { 2 - 3 } & Kafe \\
\hline & Seminar & G. Serbaguna \\
\cline { 2 - 3 } & $\begin{array}{l}\text { Makan dan } \\
\text { Minum }\end{array}$ & Restoran \\
\cline { 2 - 3 } & Menginap & Cottage \\
\hline & Belanja & Kios \\
\cline { 2 - 3 } & Bermain & Playground \\
\hline
\end{tabular}

Pada Tabel 2. dapat diketahui ruang-ruang yang dibutuhkan untuk mewadahi kegiatan pengunjung dalam Agrowisata Kopi.

\subsection{Analisis Lokasi}

Pemilihan lokasi dilakukan melalui beberapa pertimbangan yang sangat mendukung dan menentukan prospek Agrowisata Kopi.
a. Tujuan
Mendapatkan lokasi yang sesuai dengan Agrowisata Kopi
b. Dasar pertimbangan:
Dekat atau berada di area perkebunan kopi, mudah dijangkau dari JL. Parakan
- Wonosobo, merupakan peruntukkan kawasan budidaya pariwisata, memiliki kemiringan lereng yang landai(8 - $15 \%)$, memiliki pemandangan Gunung Sindoro dan Gunung Sumbing.

\subsection{Analisis Pencapaian}

Pencapaian ke dalam kawasan harus mudah diakses dari JL.Parakan Wonosobo, mudah dilihat, dan adanya pemisah akses keluar dan masuk antara pengunjung dan pengelola agar tidak terjadi crossing.

Tujuan: Menentukan main entrance dan service entrance

1. Dasar Pertimbangan: kemudahan akses dari JL. Parakan - Wonosobo, kebutuhan dan kenyamanan pengguna, dan kondisi eksisting jalan pada tapak

2. Proses analisis

Main Entrance (ME)

Mudah dijangkau dari JL. Parakan Wonosobo dan terlihat dengan jelas. Menghadap langsung ke arah jalan untuk kemudahan sirkulasi kendaraan masuk dan keluar tapak dan digunakan untuk akses masuk pejalan kaki, kendaraan bermotor, dan bus.

\section{Side Entrance (SE)}

Tidak mengganggu keberadaan ME. Membantu sirkulasi pengunjung.

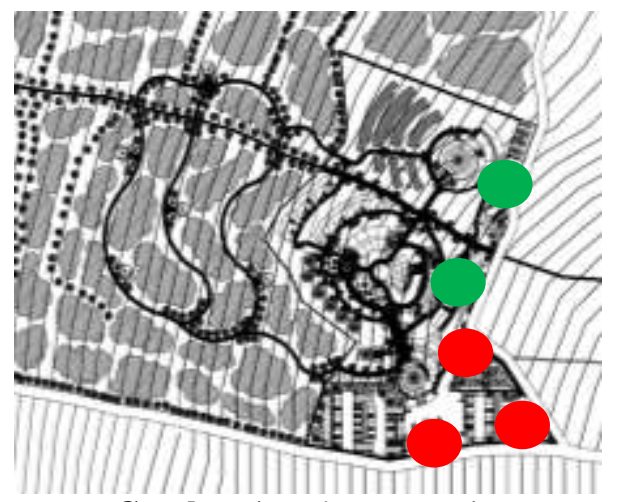

Gambar 1. Pola Pencapaian

Pada Gambar 1. terlihat pemisahan pola pencapaian untuk pengunjung dan pengelola Agrowisata Kopi.

\subsection{Analisis Pemintakatan (Penzoningan)}

Penentuan pemintakatan berdasarkan sifat kegiatan, potensi view, tingkat kebisingan, dan kondisi iklim dalam tapak.

1. Tujuan: Menentukan mintakat (zoning) berdasarkan sifat kegiatan, potensi view, tingkat kebisingan, dan kondisi iklim dalam tapak.

2. Dasar pertimbangan: analisis peruangan, dan pengolahan tapak.

3. Proses analisis: menentukan mintakat terhadap persyaratan ruang berdasarkan kelompok kegiatan dan analisis pengolahan tapak.

Gambar 2. menunjukkan pemintakatan dibedakan menjadi lima bagian, yaitu zona penerima, zona edukasi, zona rekreasi dan akomodasi, zona pengelola, dan zona service dan maintenance. 


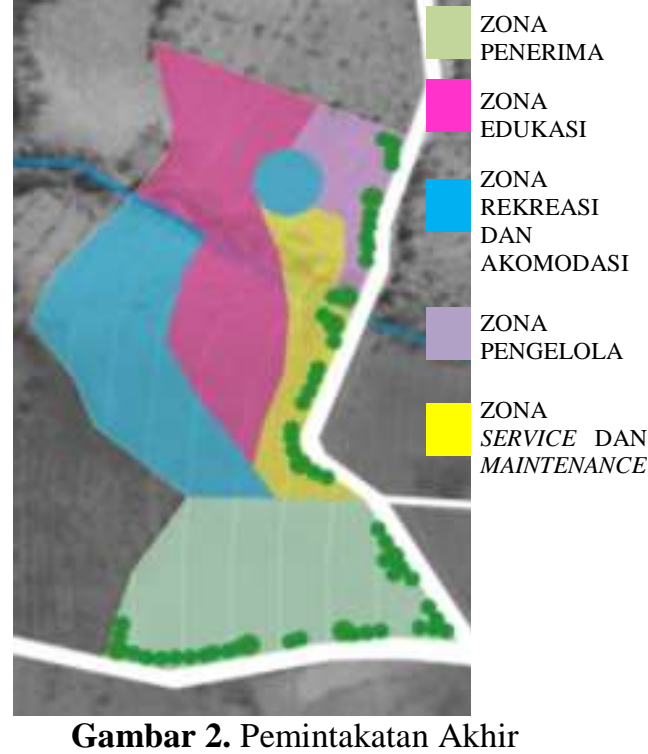

3.5 Analisis Bentuk dan Tata Massa

Tujuan: menentukan bentuk dan tata massa yang memiliki respon terhadap kondisi tapak yang berkontur, iklim setempat, dan bentukbentuk yang terdapat di sekitar tapak.

1. Dasar pertimbangan: kondisi tapak yang berkontur, kebutuhan setiap massa bangunan, iklim setempat, dan bentuk segitiga yang terdapat di sekitar tapak.

2. Proses analisis

a. Menggunakan bentuk massa yang mengadaptasi bentuk gunung dapat dilihat pada Lampiran 1, bentuk massa yang fungsional untuk kegiatan pengolahan kopi dapat dilihat pada Lampiran 2 dan Lampiran 3, dan bentuk massa yang mengalami gubahan sesuai kebutuhan akan pencahayaan dan penghawaan alami serta penyesuaian kebutuhan ruang dapat dilihat pada Lampiran 4 dan Lampiran 5.

b. Menerapkan tata massa jamak sesuai kontur untuk mengurangi cut and fill dan sebagai respon dari kebutuhan setiap massa bangunan yang berbeda terhadap potensi view, pencahayaan dan penghawaan serta tingkat kebisingan dapat dilihat pada Gambar 3.

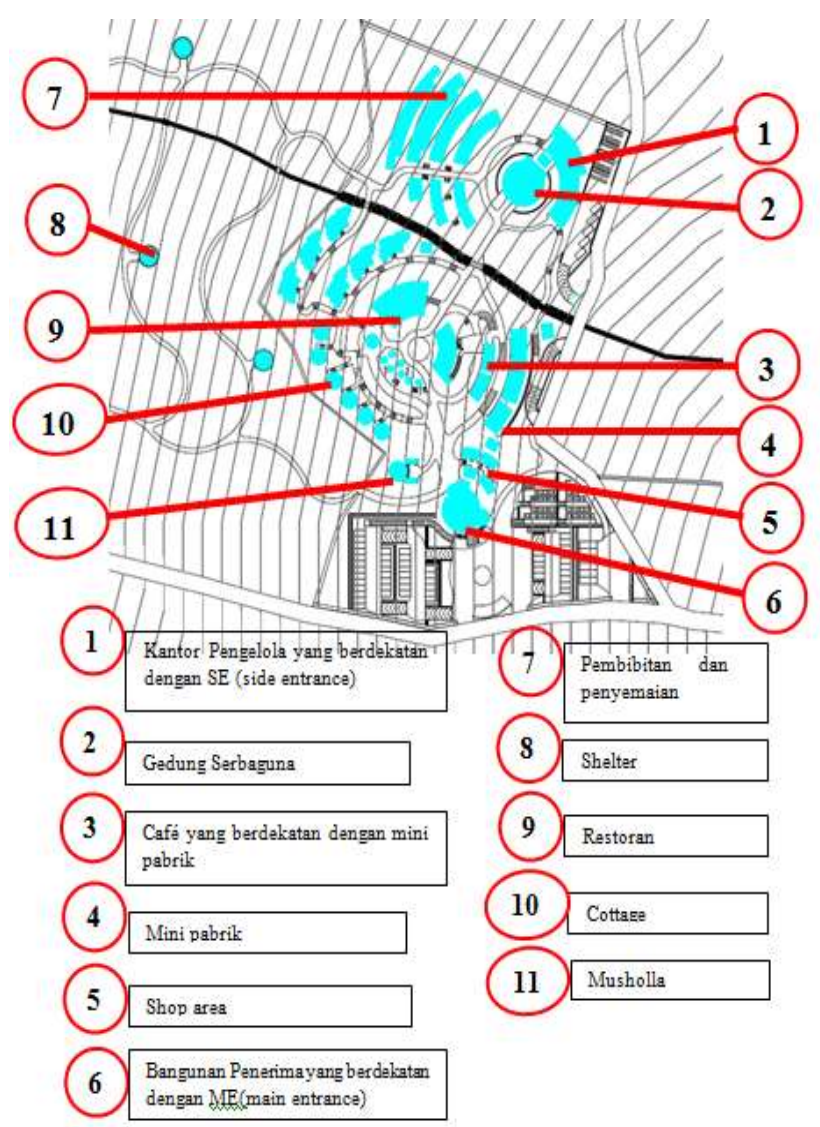

Gambar 3. Tata Massa

\subsection{Analisis Pencahayaan dan Penghawaan}

Tujuan: menentukan sistem pencahayaan alami secara optimal dan pencahayaan buatan yang hemat energi serta menentukan sistem penghawaan alami yang stabil dalam tapak secara optimal.

1. Dasar pertimbangan: kenyamanan pengguna, pencahayaan alami pada pagi sampai sore hari yang maksimal dan pencahayaan buatan yang hemat energi pada malam hari serta pergerakan angin dalam tapak.

2. Proses analisis: menerapkan bukaan horizontal dan vertikal pada bangunan sesuai dengan pergerakkan matahari dalam tapak, menghemat penggunaan energi listrik pada malam hari dengan solar lamp serta menerapkan desain bangunan dengan bentuk aerodinamik atau struktur panggung untuk menjamin pergerakan udara dalam tapak dan memanfaatkan elemen vegetasi untuk menyegarkan dan mengurangi kecepatan angin dari arah barat dan timur. 


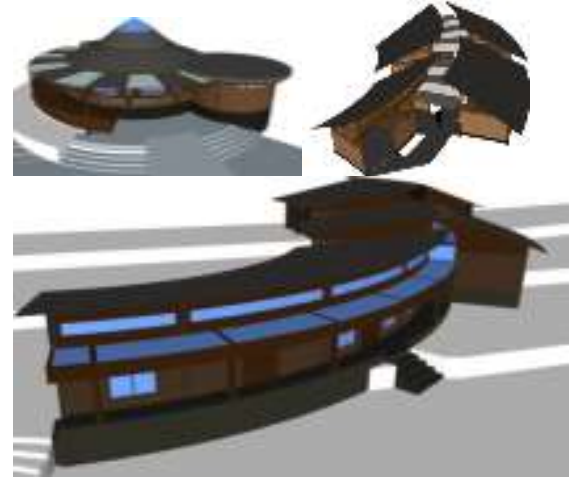

Gambar 4. Bukaan pada bangunan

Pada Gambar 4. terlihat penerapan bukaan horizontal berupa jendela dengan besar 10$20 \%$ dari luas dinding dan penerapan bukaan vertikal berupa skylight untuk mengoptimalkan pencahayaan alami pada pagi sampai sore hari.

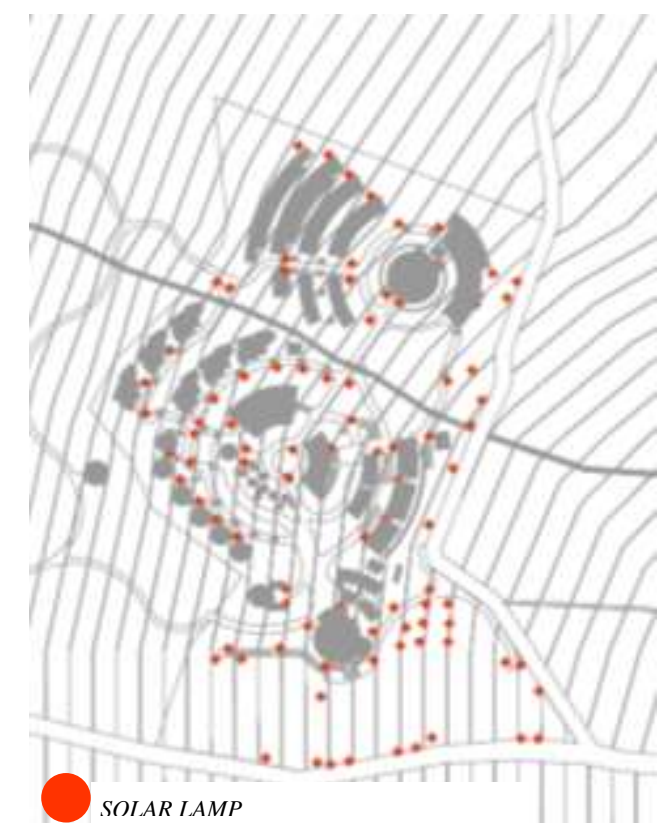

Gambar 5. Solar lamp dalam kawasan

Pada Gambar 5. terlihat penggunaan solar lamp yang mengubah energi cahaya matahari pada pagi sampai sore hari menjadi energi listrik untuk digunakan sebagai pencahayaan buatan dalam kawasan pada malam hari untuk menghemat penggunaan energi.
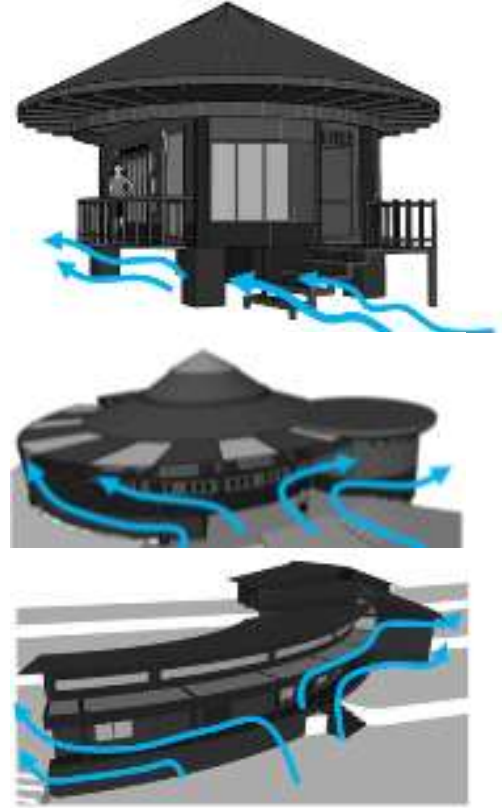

Gambar 6. Struktur Panggung dan Bentuk yang Aerodinamik

Pada Gambar 6. terlihat penerapan struktur panggung dan bentuk bangunan yang melengkung sehingga aerodinamik terhadap pergerakkan udara dalam tapak.

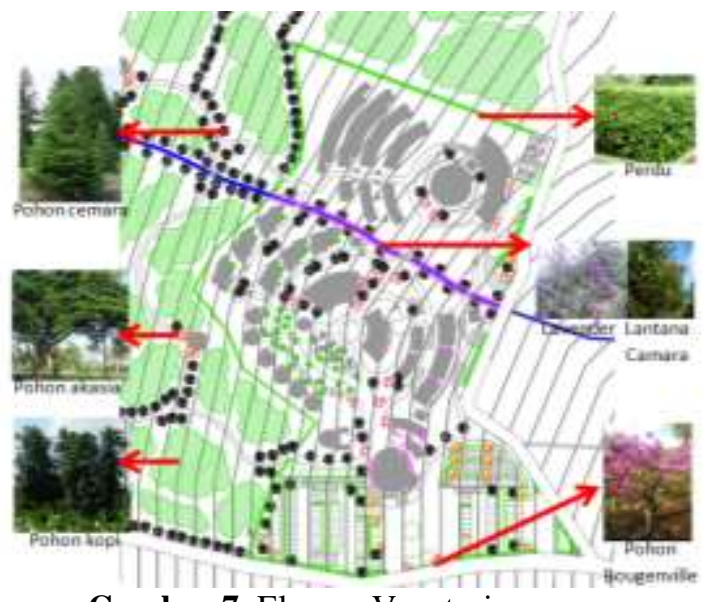

Gambar 7. Elemen Vegetasi

Pada Gambar 7. terlihat penerapan elemen vegetasi berupa cemara, pohon kopi, akasia, bougenville, tanaman lavender, lantana camara, dan perdu dalam kawasan untuk menyegarkan dan mengurangi kecepatan angin dari arah timur dan barat.

\subsection{Analisis Material Bangunan}

1. Tujuan: mendapatkan penggunaan material yang sesuai dengan 
penerapan Arsitektur Ekologi dan kebutuhan setiap massa bangunan.

2. Dasar pertimbangan: penerapan Arsitektur Ekologi dengan memilih material yang hemat energi, dapat dibudidayakan kembali, digunakan kembali, dan mengalami perubahan sederhana serta kebutuhan setiap massa bangunan.

3. Proses analisis

a. Menggunakan material lokal seperti bambu, kayu jati, batu bata dan batu kali sehingga menghemat energi dalam proses pengangkutan, mudah diterapkan, dan sesuai dengan iklim setempat.

b. Menggunakan material yang sesuai dengan kebutuhan massa bangunan untuk pembibitan dan persemaian serta pengeringan biji kopi.

c. Memanfaatkan ranting kopi yang merupakan hasil pemangkasan cabang kopi pada elemen eksterior.

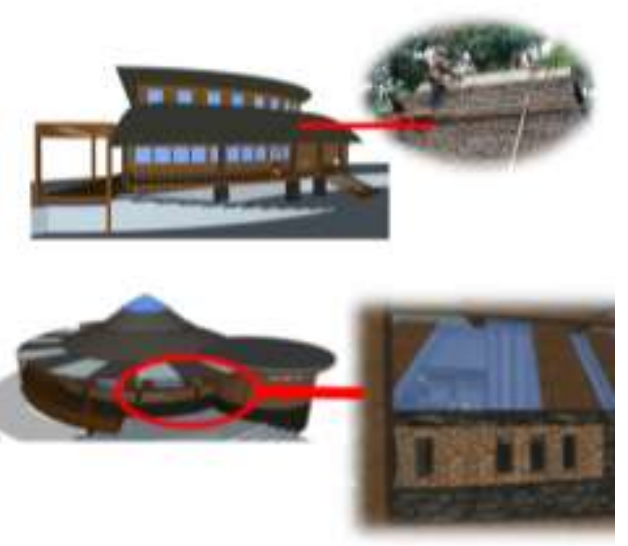

yang mampu menyerap panas matahari dengan baik, serta jalan trasah dengan material batu kali sebagai sirkulasi dalam kawasan yang mampu menyerapankan air ke dalam tanah.

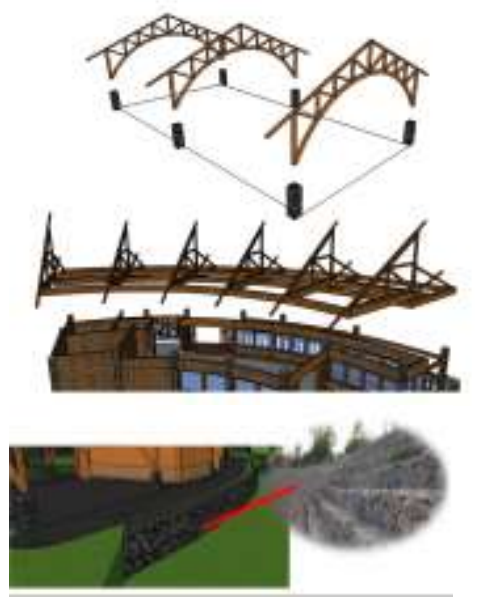

Gambar 9. Struktur Kayu Jati dan Batu Kali

Gambar 9. menunjukkan penggunaan kayu jati sebagai rangka atap dan kolom pada bangunan serta penggunaan batu kali sebagai tembok penahan tanah untuk menstabilkan kondisi tanah yang berkontur.
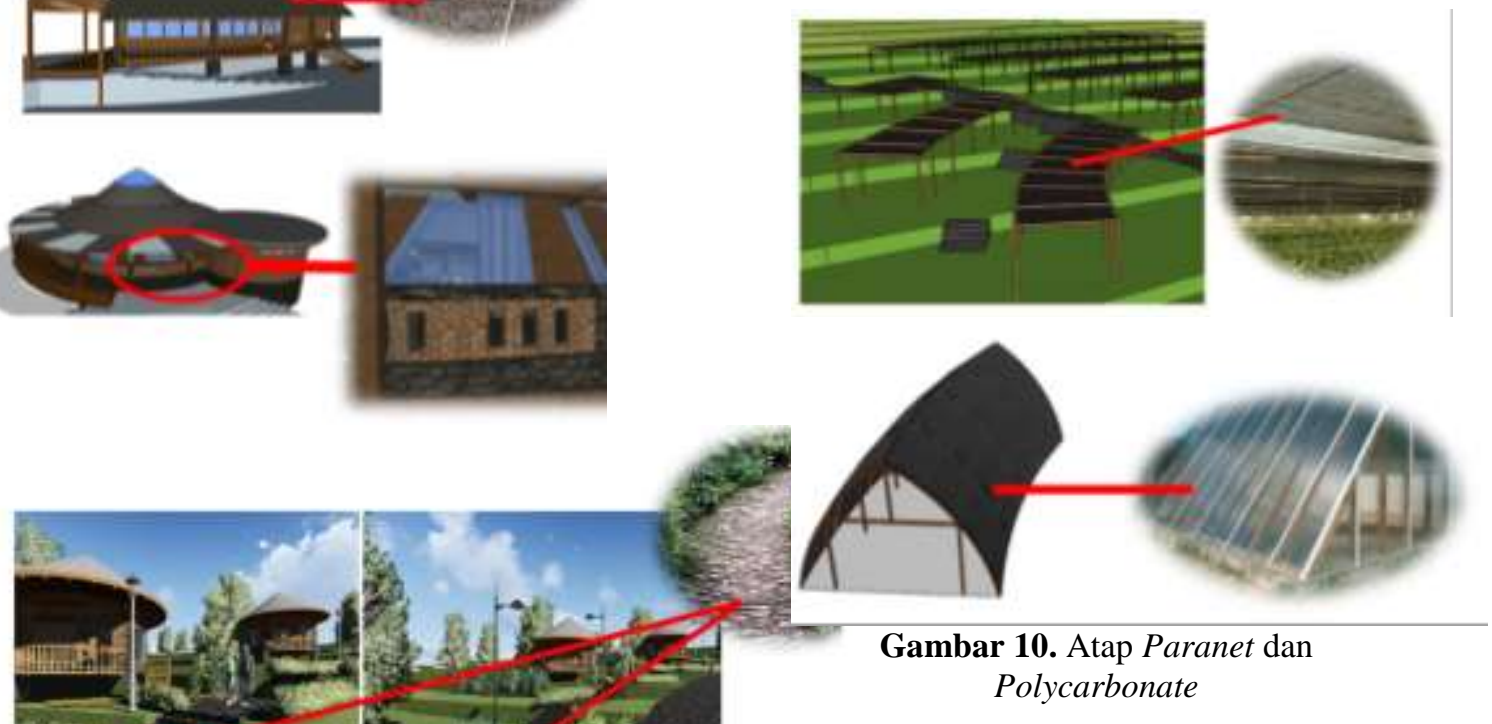

Gambar 10. menunjukkan penggunaan atap paranet yang dapat mengontrol intensitas cahaya matahari yang dibutuhkan oleh tanaman pada bangunan pembibitan dan persemaian serta penggunaan polycarbonate yang mampu menyerap panas dan menciptakan
Gambar 8. menunjukkan penggunaan bambu sebagai material penutup atap berupa sirap, penggunaan kayu, batu bata, dan batu kali yang dikombinasikan sebagai material dinding 
temperatur udara yang cukup tinggi pada bangunan pengeringan biji kopi.

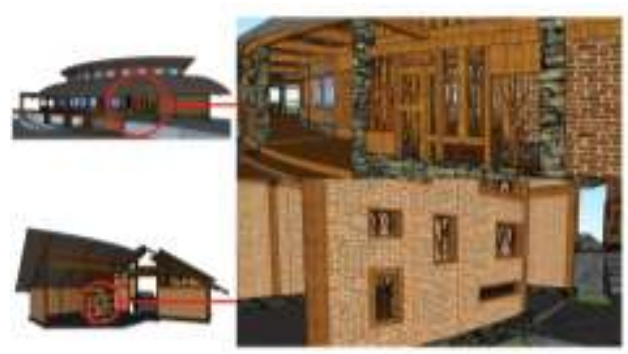

Gambar 11. Ranting Kopi

Pada Gambar 11. terlihat pemanfaatan limbah kopi berupa ranting kopi pada dinding bangunan.

\subsection{Analisis Utilitas}

1. Tujuan: mendapatkan sistem utilitas terutama jaringan air kotor, drainase air hujan, limbah kopi, dan pembuangan sampah.

2. Dasar pertimbangan: penerapan Arsitektur Ekologi dengan memanfaatan kembali limbah yang dihasilkan sehingga tidak mencemari lingkungan.

3. Proses analisis :
a. Mengolah kembali grey water menggunakan aquatic sawage treatment sehingga dapat digunakan kembali untuk flushing toilet, dan air untuk outdoor hydrant.

b. Mengondisikan air hujan agar terserap ke dalam tanah untuk menjaga kandungan air tanah.

c. Mengolah kembali limbah kopi yang dihasilkan dari proses pengolahan kopi.

d. Mengolah kembali sampah organik sebagai pupuk kompos yang bermanfaat bagi perkebunan.

Gambar 12. menunjukkan sistem jaringan air kotor salah satunya adalah pengolahan grey water yang berasal dari limbah air bekas cuci dan mandi yang disalurkan ke kolam pengolahan grey water untuk diolah kemudian digunakan kembali untuk flushing toilet, dan air untuk outdoor hydrant.

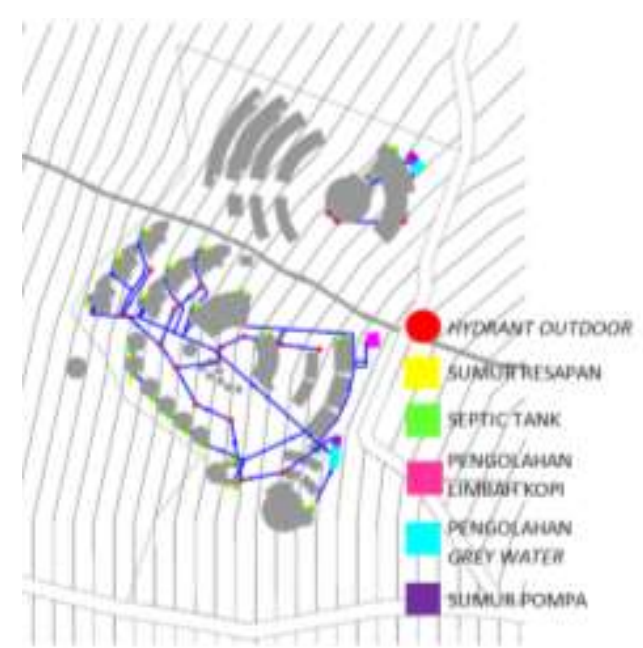

Gambar 12. Sistem Jaringan Air Kotor

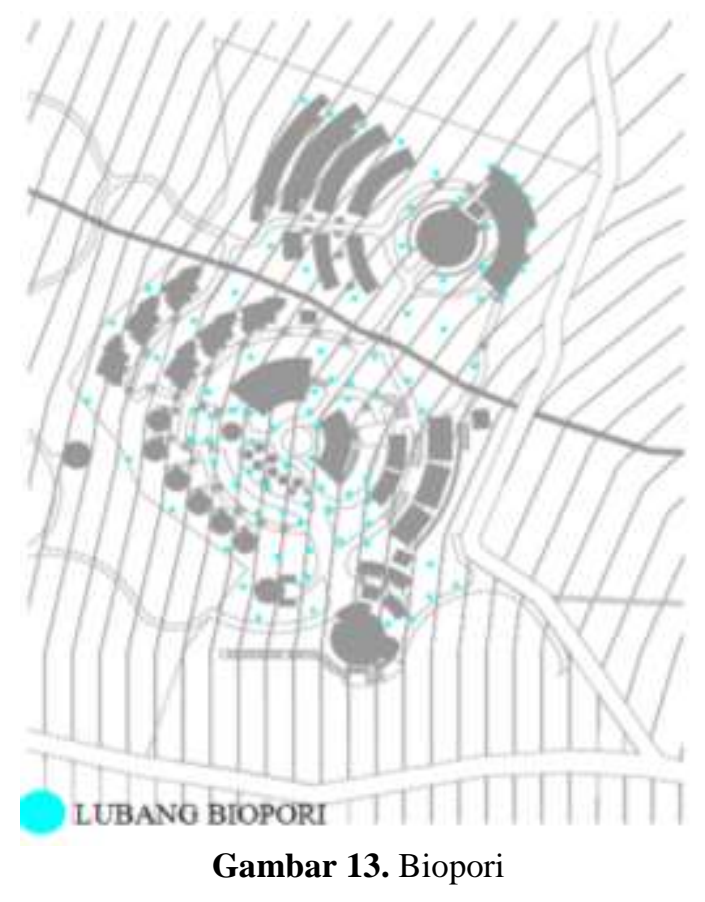

Gambar 13. menunjukkan peletakan lubang biopori dalam kawasan Agrowisata Kopi sebagai lubang peresapan air hujan untuk menjaga kandungan air tanah. 


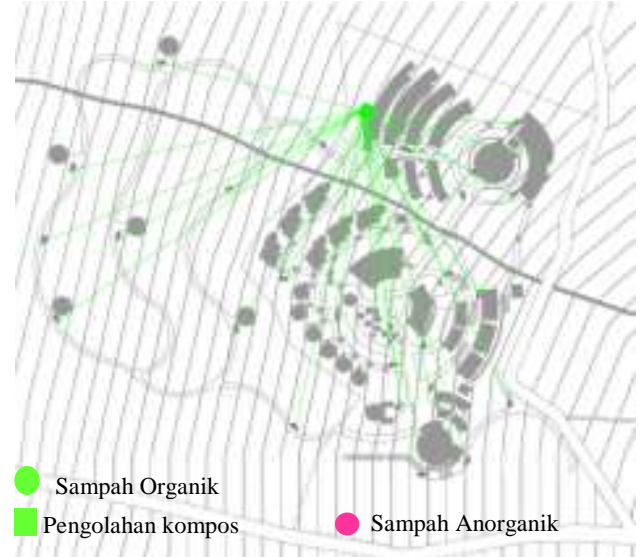

Gambar 14. Sistem Jaringan Sampah

Gambar 14. menunjukkan sistem jaringan sampah salah satunya adalah pengolahan kompos organik yang berasal dari sampah organik dalam kawasan Agrowisata Kopi.

\section{KESIMPULAN (KONSEP DESAIN)}

Konsep rancangan Agrowisata Kopi mengacu pada pendekatan Arsitektur Ekologi yang lebih fokus pada efisiensi penggunaan energi, meminimalkan cut and fill, dan manajemen limbah. Agrowisata Kopi dirancangan untuk mewadahi kegiatan edukasi dan rekreasi mengenai tanaman kopi serta mengikuti rencana pemerintah setempat. Pengolahan dan penataan massa peruangan yang sesuai dengan kebutuhan setiap massa bangunan, dan meminimalkan cut and fill dapat dilihat pada Lampiran 5.

Nama Stadion : Agrowisata Kopi Kledung

Lokasi : Jl. Parakan-Wonosobo, Desa

Tlahap Kledung Kabupaten Temanggung
Luas Lahan
: $27.373,49 \mathrm{~m}^{2}$
Luas Bangunan : $9.231,96 \mathrm{~m}^{2}$
Daya Tampung : \pm 400 orang

Kegiatan : Edukasi dan rekreasi

Gambar 15. merupakan eksterior bangunan yang dilihat dengan perspektif mata burung yang menunjukan desain bangunan dan pengolahan tapak di sekitar bangunan. Pengolahan tapak mempertimbangkan penerapan Arsitektur Ekologi, seperti meminimalisir cut and fill, dan penyerapan air ke dalam tanah.

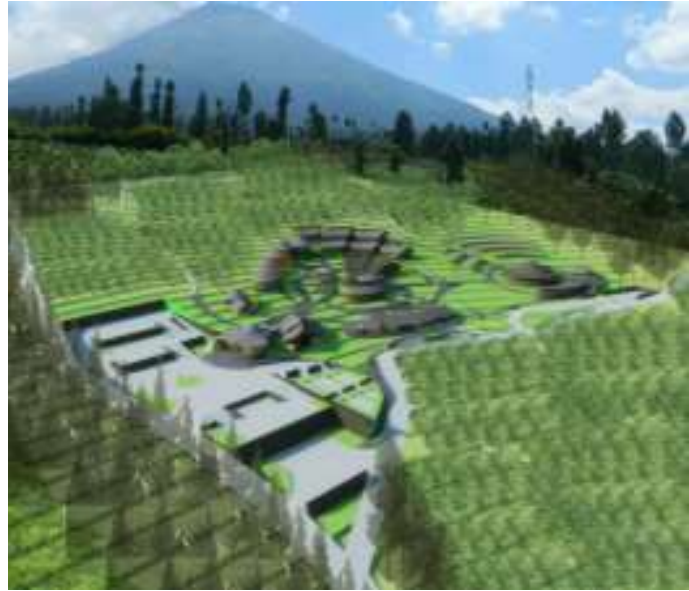

Gambar 15. Eksterior Kawasan Agrowisata Kopi

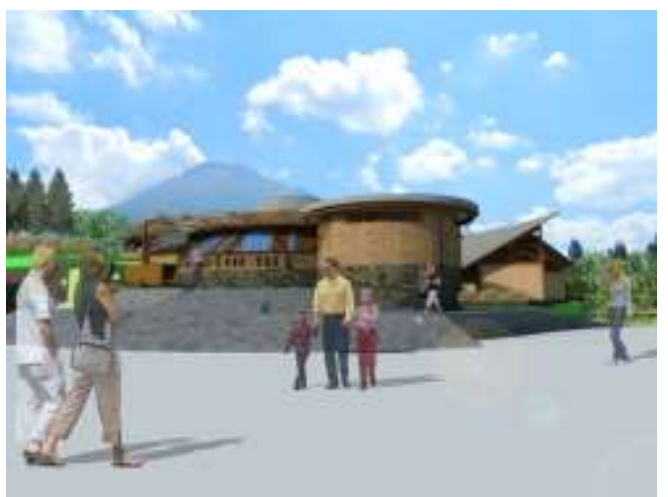

Gambar16. Eksterior Banguna Penerima

Gambar 16. eksterior bangunan penerima dengan desain yang menerapkan material lokal (batu bata, batu kali,kayu dan bambu) serta mengoptimalkan pencahayaan serta penghawaan alami.

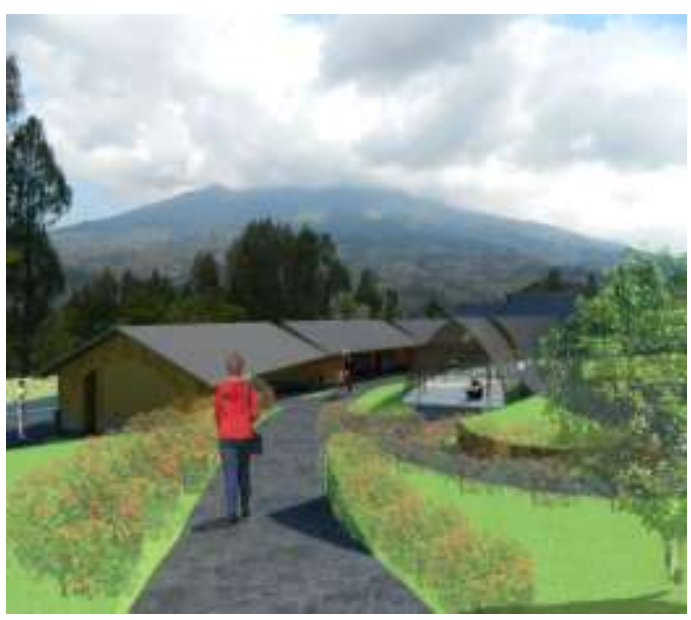

Gambar 17. Eskterior Mini Pabrik

Gambar 17. merupakan eksterior mini pabrik yang menunjukkan penggunaan massa 
bangunan yang fungsional sesuai kebutuhan kegiatan pengolahan kopi.

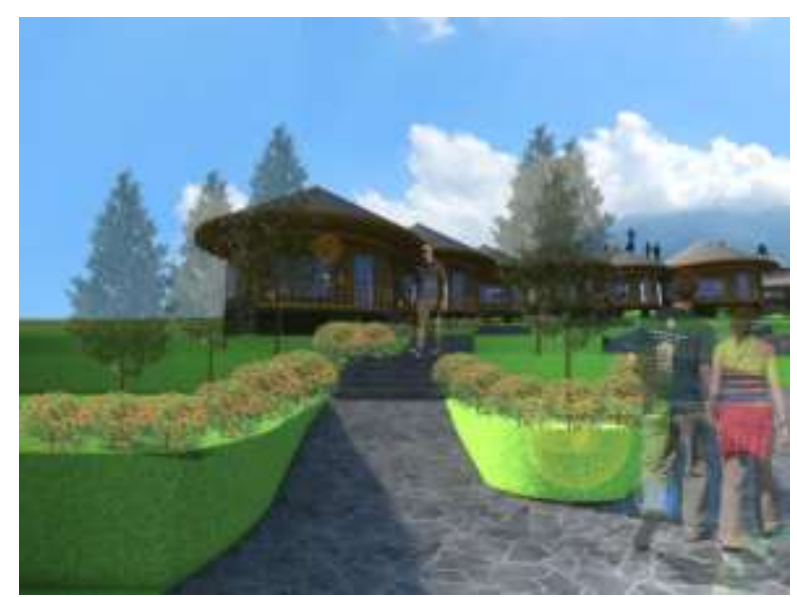

Gambar 18. Eskterior Cottage

Gambar 18. menunjukkan penerapan material lokal pada bangunan cottage dan struktur panggung sebagai respon terhadap tapak yang berkontur dan untuk mengoptimalkan pergerakkan udara dalam kawasan.

\section{REFERENSI}

RPJMD Kabupaten Temanggung Tahun 2013 $-2018$

RTRW Kabupaten Temanggung Tahun 2011 2031

Temanggung Dalam Angka 2014

Utama, IGusti Bagus Rai.2014.Pengantar Industri Pariwisata. Yogyakarta: Deepublish

Frick, H.FX., dan Bambang Suskiyanto.1998.Dasar-Dasar EkoArsitektur. Yogyakarta: Penerbit Kanisius 


\section{LAMPIRAN}
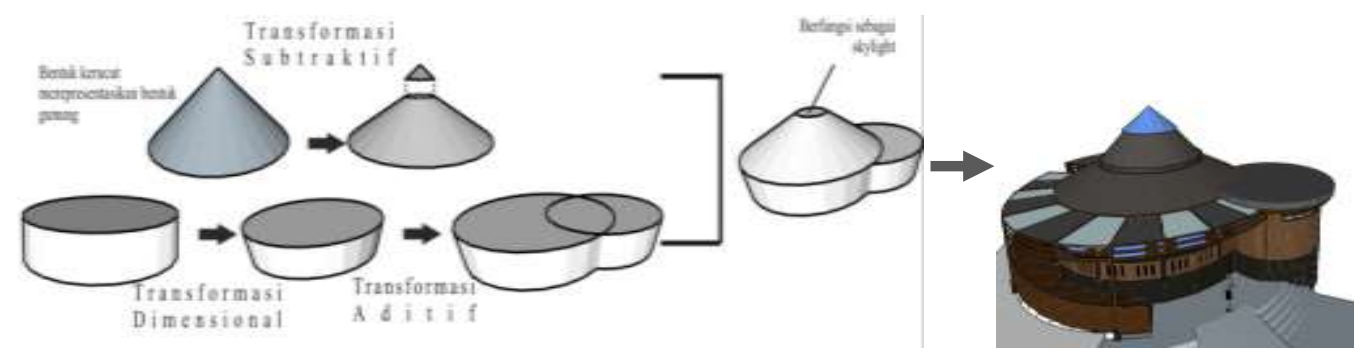

Lampiran 1. Bentuk bangunan penerima mengadaptasi bentuk gunung yang mengalami transformasi bentuk agar tidak monoton dan responsif terhadap iklim

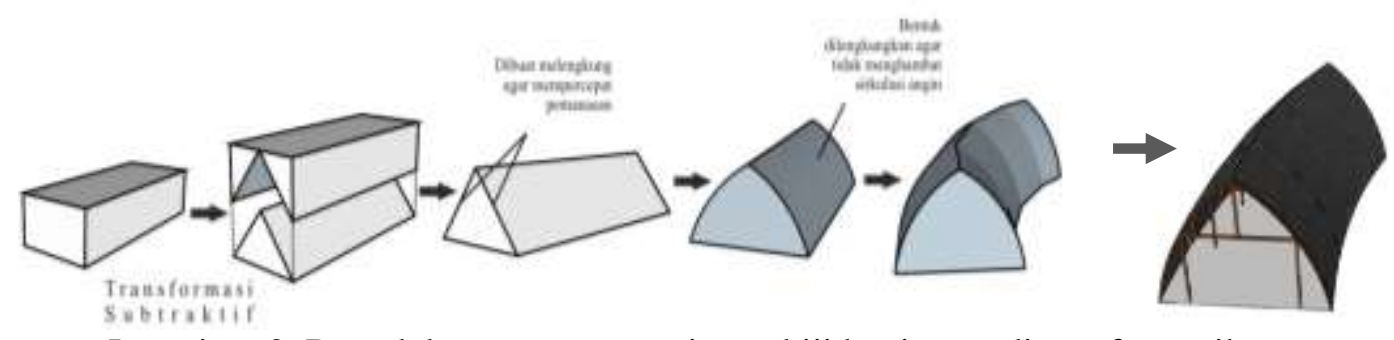

Lampiran 2. Bentuk bangunan pengeringan biji kopi yang ditransformasikan agar mempercepat pemanasan dan memiliki respon terhadap iklim (pergerakkan angin)

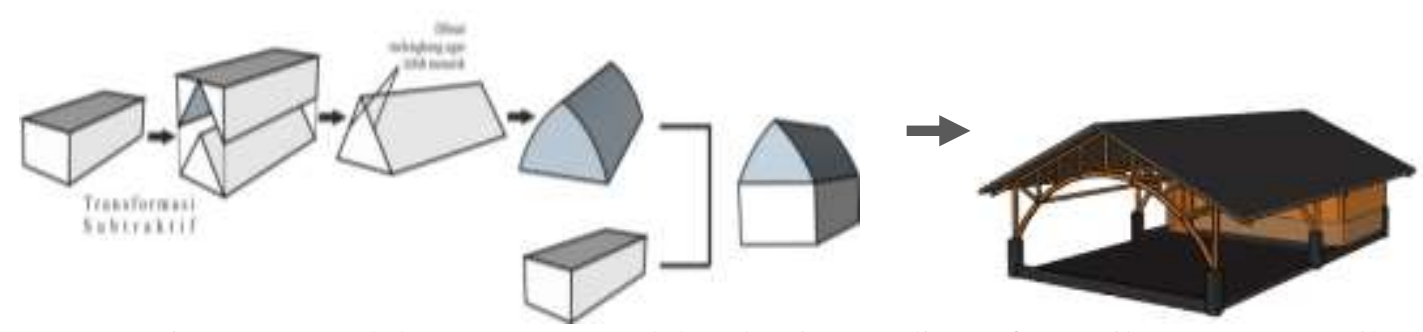

Lampiran 3. Bentuk bangunan pengolahan kopi yang ditransformasikan agar menarik namun tetap sesuai dengan fungsinya

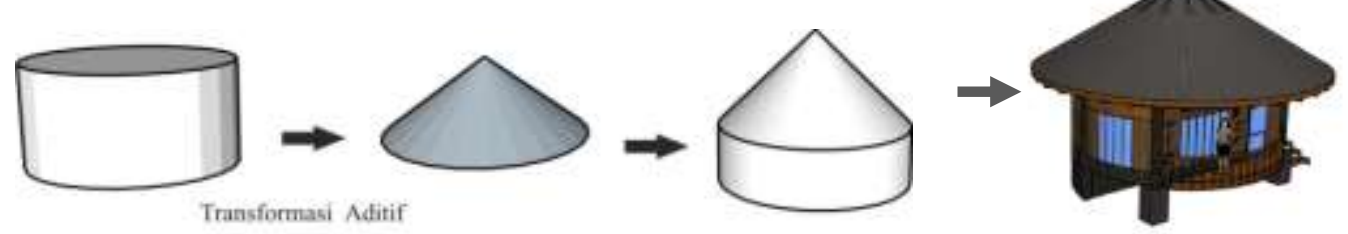

Lampiran 4. Bentuk bangunan single cottage yang merupakan perpaduan bentuk tabung
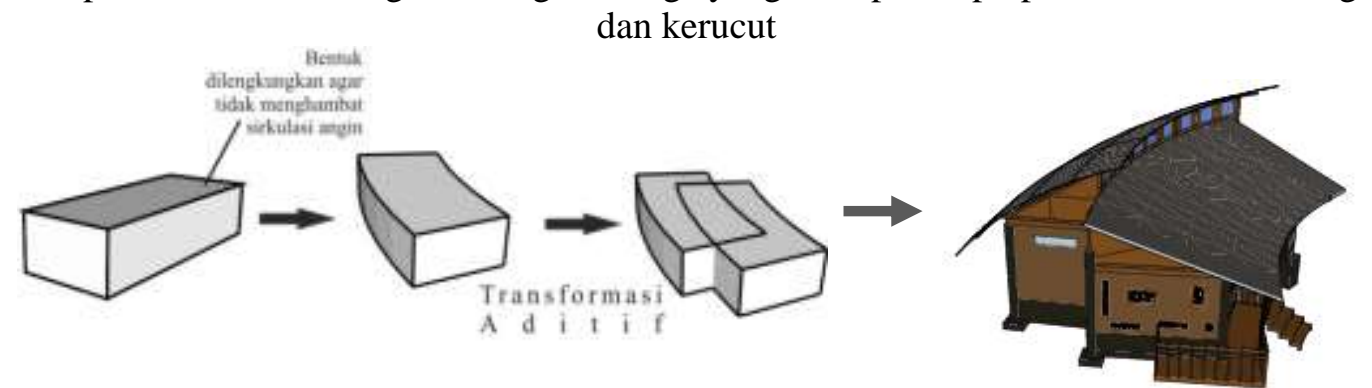

Lampiran 5. Bentuk bangunan family cottage yang ditransformasikan agar memiliki respon terhadap iklim dan menarik 


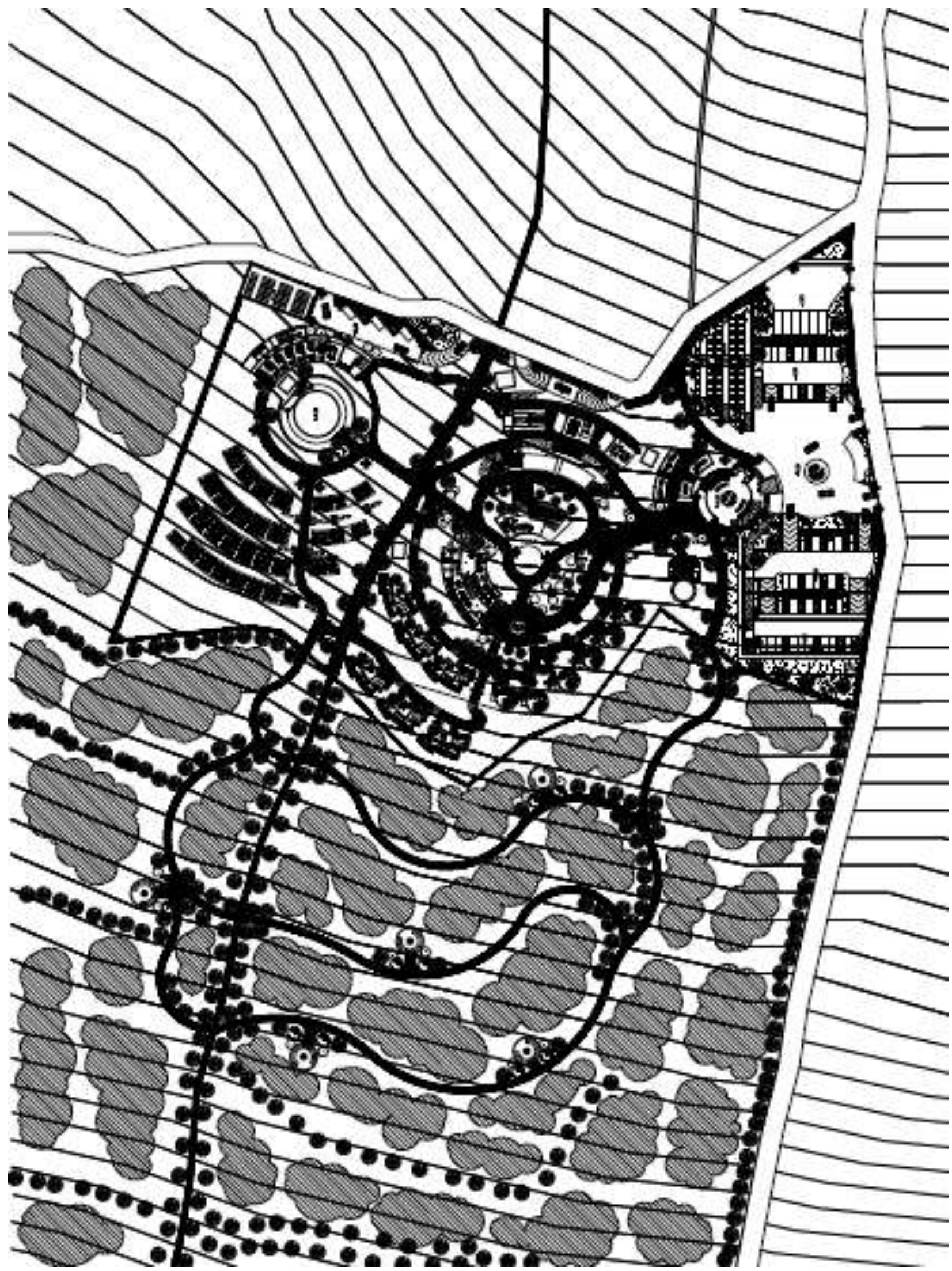

Lampiran 6. Rencana Tapak 
